\section{Broadly tunable quantum-dot based ultrashort pulse laser system with different diffraction grating orders}

A. Alhazime, Y. Ding, D.I. Nikitichev, K.A. Fedorova, I.L. Krestnikov, M. Krakowski, E.U. Rafailov

We study a broadly tunable quantum-dot based ultrashort pulse master oscillator power amplifier with different diffraction grating orders as an external-cavity resonance feedback. A broader tuning range, narrower optical spectra as well as higher peak power spectal density (maximun of $1.37 \mathrm{~W} / \mathrm{nm}$ ) from the $2^{\text {nd }}$-order diffraction beam are achieved compared to those from the $1^{\text {st }}$-order diffraction beam in spite of slightly broader pulse duration from the $2^{\text {nd }}$-order diffraction.

Introduction: High-power semiconductor ultrashort pulse laser systems with wide wavelength and/or broad pulse repetition rate tunability are very useful for non-linear imaging techniques [1], especially in the biomedical field [2]. The wide tunability offered by the quantum-dot (QD) diode lasers, due to the temperature insensibility, ultrafast carrier dynamics and broad gain bandwidth [3,4], is very promising for the development of broadly tunable high-power picosecond source. Due to the merits of the diffraction grating as the external-cavity feedback, extremely broad wavelength tunability from a pulse laser could be achieved using diffraction grating techniques [5,6]. In this paper, a tunable master oscillator power amplifier (MOPA) picosecond optical pulse source using all chirped QD structures was investigated. The MOPA system consisted of a QD external-cavity passively modelocked laser (ECMLL) and a tilted QD semiconductor optical amplifier (SOA). A comparison between the $1^{\text {st }}$ and $2^{\text {nd }}$ grating diffraction orders for this wavelength tunable QD-MOPA was further investigated. A broader tuning range, narrower optical spectra can be obtained from the configuration with the $2^{\text {nd }}$-order of grating diffraction. Peak power spectral density achieved with the $2^{\text {nd }}$-order of grating diffraction is much higher ( 2-3 times) than that from the $1^{\text {st }}$-order of grating diffraction under the similar operation conditions. The narrowest pulse of $\sim 14 \mathrm{ps}$ and the better dynamic contrast of RF spectra were observed from the setup with the $1^{\text {st }}$-order of grating diffraction.

The scheme of the experimental setup is shown in Fig. 1. The tunable MOPA setup consists of a master laser and an optical amplifier to boost the output power, where the master laser is a QD-ECMLL and the optical amplifier is a QD-SOA.

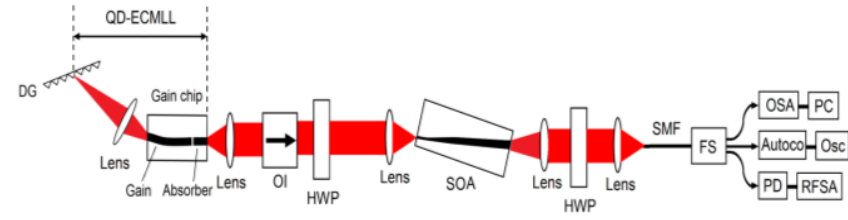

Fig. 1 Configuration of a tunable MOPA system and measurement setup, consisting of diffraction grating (DG); optical isolator (OI); half wave plate (HWP); single-mode fibre (SMF); fibre splitter (FS); optical spectrum analyser (OSA); autocorrelator (Autoco); oscilloscope (Osc); photo detector ( $P D)$; RF spectrum analyser (RFSA).

The detailed description of the scheme of the experimental setup and the MOPA system can be found in Ref. 4. In brief, the twosectional gain chip had a total length of $4 \mathrm{~mm}$ with an $800-\mu \mathrm{m}$-long absorber section placed near the front facet, and a ridge waveguide width of $6 \mu \mathrm{m}$ with $7^{\circ}$ tilting from the normal direction of the cleaved facet. Both facets of the gain chip had conventional anti-reflective (AR) coating, which resulted in total estimated reflectivities of $\sim 10^{-5}$ for the rear facet and $\sim 10^{-2}$ for the front facet. The active region of the gain chip consists of 10 non-indentical InAs QD layers, similar to that described in [7]. The SOA had a length of $6 \mathrm{~mm}$ and a gain guided waveguide width changing from $14 \mu \mathrm{m}$ at the input facet to $80 \mu \mathrm{m}$ at the output facet. The tapered SOA was fabricated from the wafer with the same epitaxial structure as the gain chip. Both the gain chip and the
SOA were kept at $20^{\circ} \mathrm{C}$ by Peltier coolers. The diffraction grating (DG) had a blaze wavelength of $1.25 \mu \mathrm{m}$ and groove density of 600 grooves $/ \mathrm{mm}$. Broad wavelength tunability in the mode locked regime was achieved under varieties of bias condition: gain chip current of 600 $\mathrm{mA}-900 \mathrm{~mA}$, reverse bias applied to the absorber section of the gain chip changing between $1 \mathrm{~V}$ and $5 \mathrm{~V}$, and SOA current of $2180 \mathrm{~mA}$.

In Fig. 2, the tuning range from both cases can be increased by increasing the injection current of the gain chip. The maximum fundamental mode-locking (FML) wavelength tuning range of nearly $100 \mathrm{~nm}$ (from $1187 \mathrm{~nm}$ to $1283 \mathrm{~nm}$ ) has been achieved under $900 \mathrm{~mA}$ current applied to the gain chip with the $2^{\text {nd }}$-order grating diffraction. In comparison, the maximum FML wavelength tuning range with a $1^{\text {st }}$ order grating diffraction is only $82 \mathrm{~nm}$ under the similar operation conditions. For a higher injection current (e.g. 1A) applied to the gain chip, we achieved 118-nm tuning range (see Fig. 3) from the $2^{\text {nd }}$-order grating diffraction. But the FML stability (from the RF linewidth and signal-to-noise ratio) under such a high current is not good as that under a relatively low current because of a faster gain recovery [8]. The investigation is still in progress.

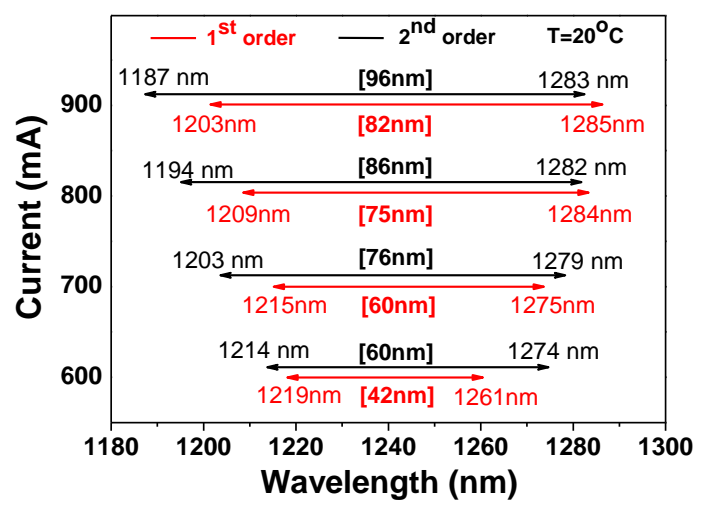

Fig. 2 Tuning range limits for the MOPA system operating in the modelocking regime for different pump currents applied to the gain chip and constant SOA current of $2180 \mathrm{~mA}$ for two configurations of the external cavity: using the $1^{\text {st }}$ (red lines) and the $2^{\text {nd }}$ (black lines) grating diffraction orders.

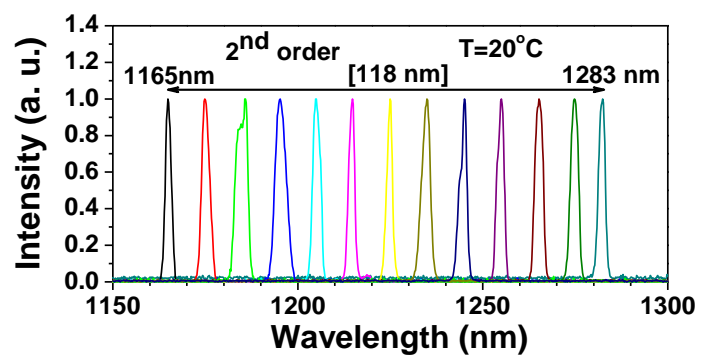

Fig. 3 Optical spectra of tunable gain chip in the mode-locked operation with gain chip current of $1 \mathrm{~A}$, reverse bias of $0-4 \mathrm{~V}$.

In theory, the output power from the configuration with the $1^{\text {st }}$-order of grating diffraction should be higher than that from the configuration with the $2^{\text {nd }}$-order, whereas, we did not find the obvious difference between the two configurations with the different DG orders. As shown in Fig. 4, the highest peak power was obtained from the MOPA with the $2^{\text {nd }}$-order grating diffraction at $1226 \mathrm{~nm}$. However, the peak power from the configuration with the $1^{\text {st }}$-order DG is higher than that from the configuration with the $2^{\text {nd }}$-order DG for the longer wavelength side (over $1230 \mathrm{~nm}$ ). The peak power changes not too much with an increasing current applied to the gain chip because the pulse duration increases with the increasing current and offsets the increase of average output power with the increasing current.

For the $2^{\text {nd }}$-order DG configuration, it can be treated as a stricter filter so that the optical spectra should be narrower than that for the $1^{\text {st }}$ order DG configuration. Correspondingly, the pulse duration from the 
setup with the $1^{\text {st }}$-order DG should be somewhat narrower than that from the setup with the $2^{\text {nd }}$-order DG. As expected, we found a fullwidth at high maximum (FWHM) of the optical spectra from the setup with the $2^{\text {nd }}$-order DG are much narrower than that from the setup with the $1^{\text {st }}$-order DG within the whole tuning range from the experiments. On the other hand, the pulse durations from both cases are similar,

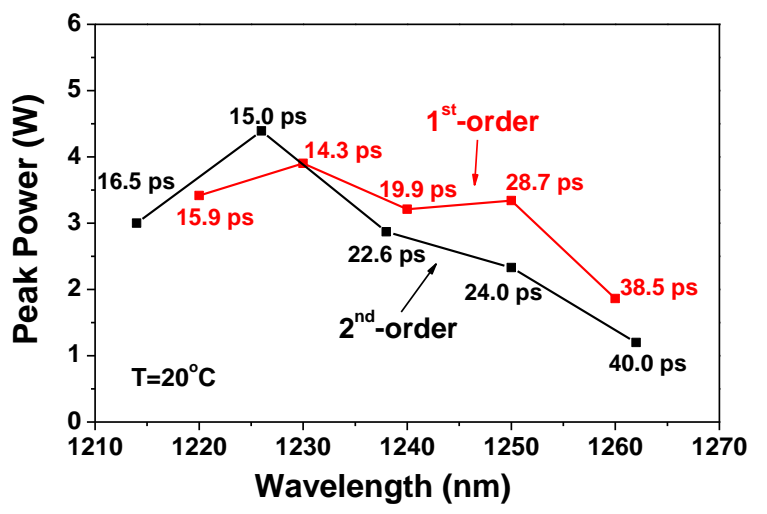

Fig. 4 Dependence of the MOPA output peak power on wavelength for the $1^{\text {st }}$ (red curve) and the $2^{\text {nd }}$ (black curve) grating diffraction orders. Gain chip and SOA currents are $600 \mathrm{~mA}$ and $2185 \mathrm{~mA}$, respectively.

although slightly broader pulse duration from the $2^{\text {nd }}$-order diffraction can be observed. The narrowest pulse of $\sim 14$ ps was found from the setup with the $1^{\text {st }}$-order DG. The dynamic contrast of RF spectra from the $1^{\text {st }}$-order DG is better than that from the $2^{\text {nd }}$-order DG which indicates the mode-locking quality from a $1^{\text {st }}$-order DG is better and each case has its own merits.

The peak power spectral density which describes how the peak power of a pulse is distributed with wavelength is very important for some applications [9]. From Fig. 5, we can see that the peak power spectral density obtained with the $2^{\text {nd }}$-order DG is much higher than that from the $1^{\text {st }}$-order DG under the similar conditions, which can be attributed to the obvious difference of FWHM of optical spectra.

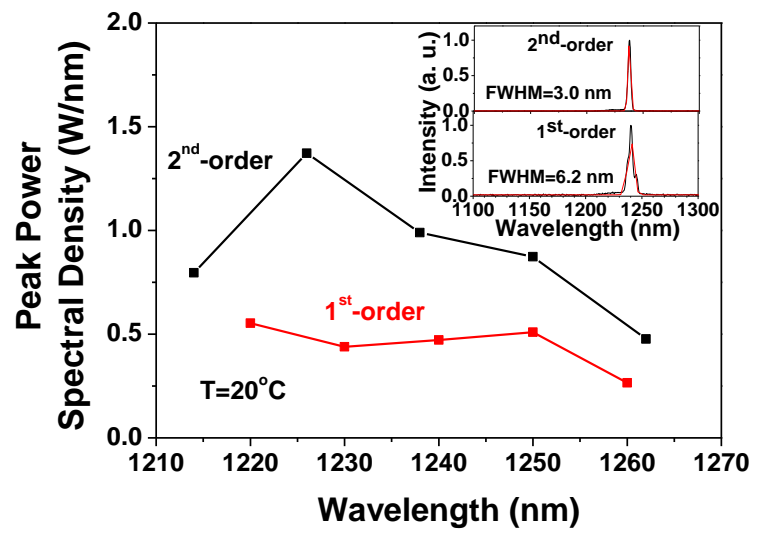

Fig. 5 Comparison of the peak power spectral density from the MOPA at different wavelengths for the $1^{\text {st }}$ (red curve) and the $2^{\text {nd }}$ (black curve) grating diffraction orders. Gain chip and SOA currents are $600 \mathrm{~mA}$ and $2185 \mathrm{~mA}$, respectively. Inset: the optical spectra from the two configurations with the different $D G$ orders.

Conclusion: From the comparison of the two configurations with the $1^{\text {st }}$-order and the $2^{\text {nd }}$-order DG, the following conclusions can be obtained: the tuning range from both cases can be increased by increasing the injection current of the gain chip. However, a broader tuning range can be achieved from configuration with the $2^{\text {nd }}$-order DG. As a trade-off, the narrowest pulse ( $\sim 14 \mathrm{ps})$ and better dynamic contrast of RF spectra can be found from the $1^{\text {st }}$-order DG. For the consideration of potential applications, the peak power spectral density obtained with the $2^{\text {nd }}$-order DG is much higher than that from the $1^{\text {st }}$-order DG under the similar conditions, which hints the $2^{\text {nd }}$-order DG is more promising.
Acknowledgments: The authors wish to acknowledge the support of the EU FP7 programme through FAST-DOT project (contract no. 224338).

A. Alhazime, Y. Ding, D. I. Nikitichev, K. A. Fedorova and E. U. Rafailov (Photonics and Nanoscience Group, School of Engineering, Physics and Mathematics, University of Dundee, Dundee, DD1 4HN, $U K)$

E-mail: A.Alhazime@dundee.ac.uk

I. Krestnikov (Innolume GmbH, Konrad-Adenauer-Allee 11, 44263 Dortmund, Germany)

M. Krakowski (III-V Laboratory, Palaiseau 91767, France)

\section{References}

1. Y. Ding, R. Aviles-Espinosa, M. A. Cataluna, D. Nikitichev, M. Ruiz, and M. Tran, Y.R., A. Kapsalis, H. Simos, C. Mesaritakis, T. Xu, P. Bardella, M. Rossetti, I. Krestnikov, D. Livshits, Ivo Montrosset, D. Syvridis, M. Krakowski, P. Loza-Alvarez, and E. Rafailov, 'High PeakPower Picosecond Pulse Generation at 1.26 $\mu \mathrm{M}$ Using a Quantum-DotBased External-Cavity Mode-Locked Laser and Tapered Optical Amplifier', Optics Express, 2012, 20, (13), pp. 14308-14320.

2. Yokoyama, H., Sato, A., Guo, H.C., Sato, K., Murc, M., and Tsubokawa, H., 'Nonlinear-Microscopy Optical-Pulse Sources Based on Mode-Locked Semiconductor Lasers', Optics Express, 2008, 16, (22), pp. 17752-17758.

3. E. U. Rafailov, M. A. Cataluna, and W. Sibbett, "Mode-locked quantum dot lasers," Nature Photon., vol. 1, pp. 395-401, Jul. 2007.

4. M. A. Cataluna, Y. Ding, D. I. Nikitichev, K. A. Fedorova, and E.U. Rafailov, "High-power versatile picosecond pulse generation from mode-locked quantum-dot laser diodes," IEEE J. Sel. Topics Quantum Electron., vol. 17, no. 5, pp. 1302-1310, Sep./Oct. 2011

5. D. I. Nikitichev, K. A. Fedorova, Y. Ding, A. Alhazime, A. Able, W. Kaenders, I.Krestnikov, D. Livshits, and Rafailov, E.U., 'Broad Wavelength Tunability from External Cavity Quantum-Dot ModeLocked Laser', Applied Physics Letters, 2012, 101, p. 121107.

6. Y. Ding, A. Alhazime, D. Nikitichev, K. Fedorova, M. Ruiz, M. Tran, Y. Robert, A. Kapsalis, H. Simos, C. Mesaritakis, T. Xu, P. Bardella, M. Rossetti, I. Krestnikov, D. Livshits, I. Montrosset, D. Syvridis, M. A. Cataluna, M. Krakowski, and Rafailov, E., 'Tunable Master-Oscillator Power-Amplifier Based on Chirped Quantum-Dot Structures', IEEE Photonics Technology Letters, 2012, 24, (20), pp. 1841-1844

7. Fedorova, K.A., Cataluna, M.A., Krestnikov, I., Livshits, D., and Rafailov, E.U., 'Broadly Tunable High-Power Inas/Gaas Quantum-Dot External Cavity Diode Lasers', Optics Express, 2010, 18, (18), pp. 19438-19443.

8. Ding, Y., Nikitichev, D.I., Krestnikov, I., Livshits, D., Cataluna, M.A., and Rafailov, E.U., 'Quantum-Dot External-Cavity Passively Modelocked Laser with High Peak Power and Pulse Energy', Electronics Letters, 2010, 46, (22), pp. 1516-1517.

9. Hagen, J., R. Engelbrecht, B. Lins, B. Schmauss, and GrunerNielsen, L., 'Optimization of the Power Spectral Density of RamanMopas Using Fiber Bragg Gratings with Tunable Chirp,' in Proceedings of the OFC/NFOEC 2008, vol. 1-8, pp. 1972-1974, San Diego, 2008. 